University of Nebraska - Lincoln

DigitalCommons@University of Nebraska - Lincoln

\title{
Ultrasonic Mapping of Hybrid Additively Manufactured 420 Stainless Steel
}

\author{
Luz D. Sotelo \\ University of Nebraska-Lincoln \\ Haitham Hadidi \\ University of Nebraska-Lincoln \\ Cody S. Pratt \\ University of Nebraska-Lincoln \\ Michael P. Sealy \\ University of Nebraska-Lincoln, sealy@unl.edu \\ Joseph A. Turner \\ University of Nebraska-Lincoln, jaturner@unl.edu
}

Follow this and additional works at: https://digitalcommons.unl.edu/mechengfacpub

Part of the Mechanics of Materials Commons, Nanoscience and Nanotechnology Commons, Other Engineering Science and Materials Commons, and the Other Mechanical Engineering Commons

Sotelo, Luz D.; Hadidi, Haitham; Pratt, Cody S.; Sealy, Michael P.; and Turner, Joseph A., "Ultrasonic Mapping of Hybrid Additively Manufactured 420 Stainless Steel" (2021). Mechanical \& Materials Engineering Faculty Publications. 622.

https://digitalcommons.unl.edu/mechengfacpub/622

This Article is brought to you for free and open access by the Mechanical \& Materials Engineering, Department of at DigitalCommons@University of Nebraska - Lincoln. It has been accepted for inclusion in Mechanical \& Materials Engineering Faculty Publications by an authorized administrator of DigitalCommons@University of Nebraska Lincoln. 


\title{
Ultrasonic Mapping of Hybrid Additively Manufactured 420 Stainless Steel
}

\author{
Luz D. Sotelo, Haitham Hadidi, Cody S. Pratt, Michael P. Sealy, \\ and Joseph A. Turner
}

Department of Mechanical and Materials Engineering, University of Nebraska-Lincoln, Lincoln, Nebraska, USA

Corresponding author - Joseph A. Turner, email jaturner@unl.edu.

Note: The current address of Haitham Hadidi is Department of Mechanical Engineering, Jazan University, Gizan, Jazan 45142, Saudi Arabia.

\begin{abstract}
Metal hybrid additive manufacturing (AM) processes are suitable to create complex structures that advance engineering performance. Hybrid AM can be used to create functionally graded materials for which the variation in microstructure and material properties across the domain is created through a synergized combination of fully coupled manufacturing processes and/or energy sources. This expansion in the engineering design and manufacturing spaces presents challenges for nondestructive evaluation, including the assessment of the sensitivity of nondestructive measurements to functional gradients. To address this problem, linear ultrasound measurements are used to interrogate 420 stainless steel coupons from three manufacturing methods: wrought, AM, and hybrid AM (directed energy deposition + laser peening). Wave speed, attenuation, and diffuse backscatter results are compared with microhardness measurements along the build/axial direction of the coupons, while microstructure images are used for qualitative verification. The ultrasound measurements compare well with the destructive measurements without any substantial loss in resolution. Furthermore, ultrasonic methods are shown to be effective for identification of the gradient and cyclic nature of the elastic properties and microstructure on the hybrid AM coupon. These results highlight the potential of ultrasound as an efficient and accessible nondestructive characterization method for hybrid AM samples and inform further nondestructive evaluation decisions in AM.
\end{abstract}


Keywords: nondestructive evaluation, wave speed, attenuation, backscatter, spatial mapping, heterogeneity

\section{Introduction}

Additive Manufacturing (AM) has shifted the paradigm of engineering design and is driving advanced manufacturing innovation [1,2]. Metal AM adopters benefit from the favorable mechanical properties of metals and access a wider design space in terms of geometric complexity, material combinations, and localized customization. Many studies have addressed various aspects of metal AM processes, from parameter selection to component characterization [3]. However, metal AM end users still need approaches to ensure the components made with these processes have the desired mechanical properties as well as methods to characterize the spatial distribution of these properties in the components nondestructively [2].

Hybrid AM is defined as the synergistic coupling of any AM process with one or more secondary processes or energy sources. Hybrid processes offer an additional design aspect to impart desired global or local properties upon a component, such as local patterning, improved global properties, and/or nontraditional behavior. Undesirable features may also be removed using hybrid processing [4]. Laser peening (LP) is a typical surface treatment used to reduce undesirable residual stresses and improve mechanical properties. For this reason, researchers have explored the incorporation of cyclical LP with AM in hybrid processes. Sealy et al. [5] and Madireddy et al. [6] used finite element simulations to report the depth of deformation and compressive residual stresses under different hybrid AM processing conditions including LP. Kalentics et al. [7] demonstrated the ability to impart compressive residual stresses experimentally in a hybrid AM (laser powder bed fusion + LP) on 316L stainless steel. Similarly, Sealy et al. [8] imparted compressive residual stresses in 420 stainless steel with a hybrid process incorporating LP and directed energy deposition (DED). They also briefly discussed some of the microstructural changes that resulted from the hybrid process, including grain refinement and increased dislocation density [8]. These results focused on a predefined location in the samples, while the hybrid interface microstructure was not shown. Nonetheless, their observations agree with LP effects observed on stainless steel welds: refined micron scale austenite grains and subgrain structures such as deformation twins and strain-induced acicular martensite [9-11].

Among nondestructive evaluation (NDE) methods, ultrasound measurements have the advantage of being a rapid and accessible approach to obtain volumetric information from a sample. In particular, linear ultrasound measurements have been used extensively to interrogate and characterize metals. Phase velocity measurements are often used to determine material elastic constants and have been applied to characterize microstructure because of the dependence of velocity with respect to crystallographic orientation [12-14]. Microstructure descriptors, such as morphology and orientation, have also been related to the ultrasonic attenuation in polycrystals [15-18]. Finally, diffuse ultrasonic backscatter (i.e., grain noise) has been shown to correlate well with the average grain diameter of polycrystalline samples, while being advantageous in the detection of defects that appear as signals above the bounds of a given grain noise baseline [19-26]. 
Ultrasonic characterization in metal AM is a growing area of study [27]. Conversely, there is abundant literature on ultrasonic NDE of welds driven by the need to improve the probability of defect detection in and/or near welded joints. Researchers have observed the directional dependence of wave speed with respect to elongation and crystallographic orientation axis as well as the increased attenuation with disorientation, anisotropy, and grain size in austenitic stainless steel welds [28-30]. Nonetheless, important differences exist between these studies and the work in this article. Weld beads in traditional welded joints are often several millimeters in size, while melt pool dimensions in typical AM parts are less than a millimeter. Solidified regions in AM experience several thermal cycles during the manufacturing process that are generally not present in welding. Also surface treatments on welds are generally performed as a post-process, while LP here is incorporated cyclically as part of the AM process.

Applications of ultrasonic NDE in metal AM have been studied for the evaluation of porosity content [31,32], microstructure characterization [33], grain size quantification [32,34], detection of changes in dislocation density [35], flaw detection [36], and in-situ/real-time monitoring [37,38]. However, NDE research for hybrid AM parts is more limited. The only example known to the authors is a study that utilized laser ultrasound surface wave speed measurements to evaluate the microstructure of Ti6Al4V samples. The samples were made with a hybrid AM process that combined wire arc additive manufacturing (WAAM) with rolling after each layer was deposited [39]. Nonetheless, due to the nature of the measurement, that study focused on the evaluation of the microstructure of multiple surfaces, which required extensive destructive sample preparation. Hybrid metal AM components are likely to have large spatial variations of microstructure. AM samples exhibit complex and heterogeneous microstructures because of the thermal gradients and the thermal cycles typically involved [40]. Hybrid metal AM samples experience even more intricate processing conditions that change the microstructure in localized regions [4]. The combination of the already complex AM microstructure with the localized microstructural changes imparted by hybrid AM processes highlights the importance of spatial maps of these properties. Furthermore, because of the expected microstructure complexity, ultrasonic responses from hybrid AM samples are challenging to predict and interpret.

The purpose of this article is to evaluate the sensitivity of linear ultrasound measurements, including wave speed, attenuation, and diffuse backscatter, to variations in the microstructure and elastic properties of hybrid metal AM samples created by a combination of DED and LP. The sensitivity of these measurements is assessed by their ability to capture the hybrid cycles in comparison with microhardness measurements as well as their ability to procure additional information. In doing so, the potential uses and limitations of linear ultrasound measurements for the characterization of hybrid AM materials are explored. For this purpose, three questions are posed: Can hybrid cycles be resolved and mapped using ultrasound? How does the resolution provided by ultrasound measurements compare with that from microhardness measurements? Does ultrasound provide any additional information? The answers to these questions are beneficial for both the scholar and practitioner AM and ultrasound communities, and highlight the utility of ultrasound measurements for evaluating complex AM domains. 


\section{Methodology}

\subsection{Manufacturing}

Three 420 stainless steel cylinders ( $12.7 \mathrm{~mm}$ in diameter and $25.4 \mathrm{~mm}$ in height) were studied. Two of these samples were made using DED, while the last was machined from conventional wrought stock material. A hybrid AM process was employed in the making of one of the samples, incorporating an asynchronous combination of LP (Powerlite DLS 8010) and DED (Optomec LENS HY20-CA). The DED parameters were $390 \mathrm{~W}$ laser power, $12 \mathrm{~mm} / \mathrm{s}$ scan speed, and $300 \mu \mathrm{m}$ layer thickness. For both AM and hybrid AM samples a total of 85 layers was printed. In the case of the hybrid AM sample, laser peening was applied every five layers (approximately $1.5 \mathrm{~mm}$ ) at $50 \%$ overlap and $500 \%$ coverage. Further details and schematics of the manufacturing process are available in [8]. The AM and hybrid AM samples were machined in a post-processing step to obtain uniform dimensions. To facilitate destructive and nondestructive characterization of AM and hybrid AM layers, all samples were ground to create two parallel faces aligned with the build direction as shown schematically in Figure 1. The final dimensions of the parallel surfaces created on the samples for microhardness and ultrasound measurements varied within and among samples because of the grinding process. The average was $25.12 \pm 0.18 \times 7.35 \pm 0.48 \mathrm{~mm}^{2}$. The sample with the shortest length was the hybrid AM sample, while that of the smallest width was the wrought sample. Note that this sample preparation, from removing the samples off the build plate to machining and grinding the sample surfaces for evaluation, was likely to have changed the stress state of the materials evaluated. However, given that all samples were similarly prepared, these effects were not expected to affect the comparisons made across samples.

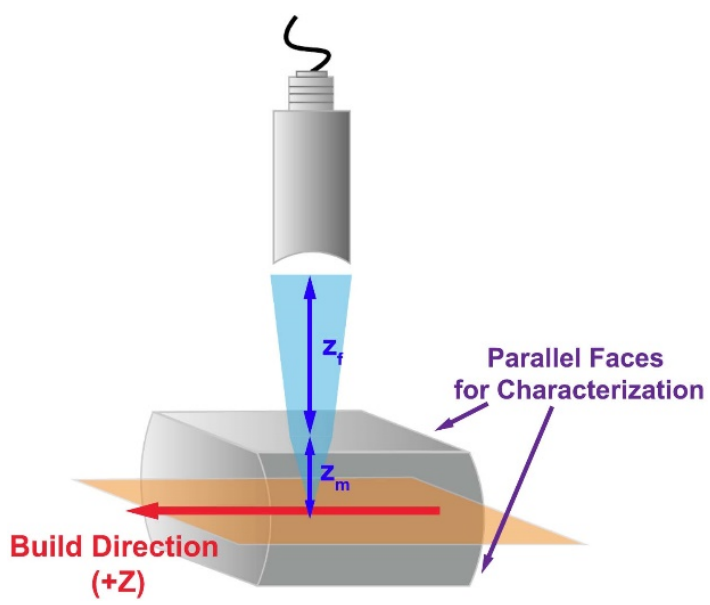

Figure 1. Schematic depicting the sample geometry as prepared for characterization, featuring the parallel faces aligned with the build direction as well as the ultrasonic experimental setup. In this schematic, $\mathrm{zf}$ is the water path and $\mathrm{Zm}$ is the material path. 


\subsection{Microstructure}

The samples were prepared following metallography procedures based on ASTM E3 and ASTM E407 [41,42]. The samples were mounted and hand polished on a rotating polishing wheel in a progression of 400, 600, 800 grit SiC paper, $9 \mu \mathrm{m}$ and $1 \mu \mathrm{m}$ diamond on an Atlantis polishing pad (PACE Technologies), and $0.05 \mu \mathrm{m}$ alumina on a Tricote (PACE Technologies) polishing pad. The samples were then etched by swabbing the polished surface with Kallings No. 2 Reagent for approximately $30 \mathrm{~s}$.

Micrographs collected at various magnifications with a laser confocal microscope (Keyence VK-X200K) and a scanning electron microscope (SEM, FEI Helios NanoLab 660) are shown in Figure 2. The laser + optical images show the general microstructure, while the SEM images provide additional details. The microstructure complexity is evident in all images. Two areas of the hybrid AM sample were investigated, namely the interface at which LP was applied and the region in between LP treatments. In the remainder of this article, the hybrid treatment interface is referred to as the "hybrid layer." In general, the microstructure of AM and hybrid AM samples can be described in terms of three main features: prior austenitic grain boundaries, parental austenitic cell colonies (dendritic and equiaxed), and martensitic laths/needles. The prior grain boundaries are likely remnants of the powder microstructure, while the austenitic and martensitic structures are a result of the material processing. 420 stainless steel is a martensitic steel used in applications requiring both corrosion resistance and hardenability. Depending on the material or manufacturing process, the thermomechanical history of 420 stainless steel may promote the formation of different phases, including FCC austenite $(\gamma)$, BCC ferrite $(\delta)$, BCT martensite $(\alpha)$, and their combinations [43]. The absence of ferrite is an important difference between $\mathrm{AM}$ and weld microstructures, which is attributed to the thermal cycles and cooling rates in AM [40,43-45]. 
(a)

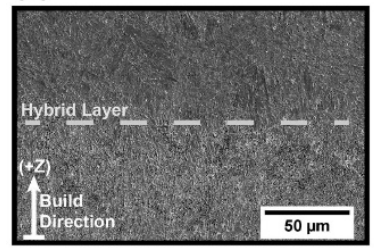

(b)

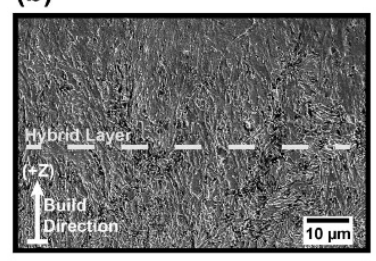

(c)

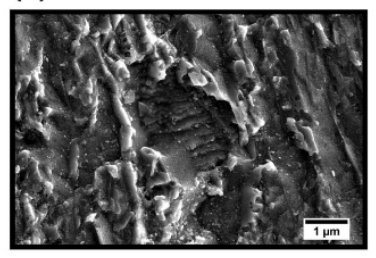

(d)

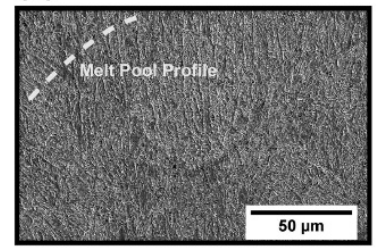

(e)

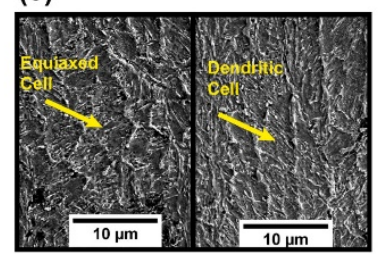

(f)

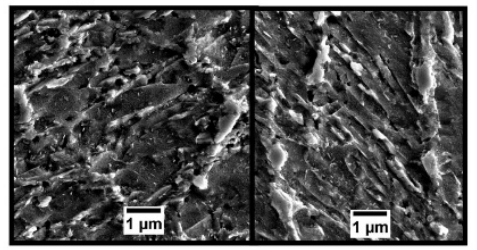

(g)

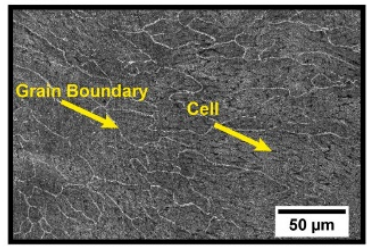

(h)

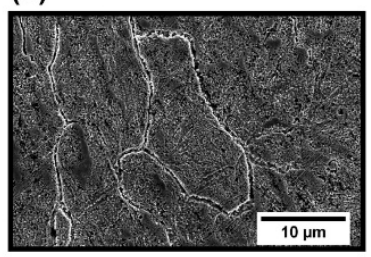

(i)

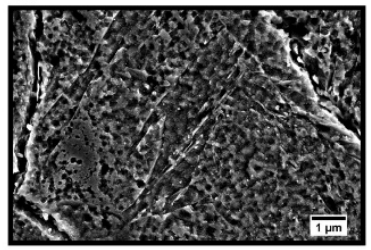

Figure 2. Laser + optical and SEM images showing the microstructure (a)-(c) on the hybrid layer, (d)-(g) in between hybrid layers, (h)-(j) of the AM sample.

The first column in Figure 2 contains images of the hybrid layer interface. Figure 2(a) shows the distinction between the microstructure below and above the hybrid layer, depicted as a dashed line. Large and refined cells are present above and below the hybrid layer, respectively. A more detailed view of the microstructure at the hybrid layer is given in Figure 2(b), where the refinement of the austenite cells below the hybrid layer is highlighted. A parental austenite cell as well as martensitic laths on the hybrid layer are shown in Figure 2(c).

Images of the microstructure between hybrid layers are displayed in the second column of Figure 2. The general microstructure of dendritic and equiaxed austenite cells is shown in Figure 2(d), where the dashed line indicates the melt pool profile. Each morphology is shown separately in Figure 2(e), as indicated by the arrows. Details of equiaxed and dendritic austenite cells are shown in Figure 2(f). These cells are larger than those seen in Figure 2(c), while martensitic laths are still present.

The general microstructure of the AM sample is shown in the third column of Figure 2(h). The large austenite grain boundaries and the austenite cells are both visible, although the cells appear fainter. This effect is likely because of a milder reaction of the microstructure to the etchant. Figure 2(i) more closely shows the overlap between both austenitic structures, and Figure 2(j) shows a detail of an austenite grain, in which fine martensite laths are observed. 
The most distinct effect of the hybrid treatment is the refinement of the microstructure, specifically the austenite cells. Additionally, martensitic laths are observed in all locations of the AM and hybrid AM samples. These observations are consistent with other published results [43-45] and with the expected effects of the hybrid treatment [8].

\subsection{Microhardness}

Vickers microhardness measurements were collected on the faces created for characterization along the build direction of the AM and hybrid AM samples (see Fig. 1). The effect of each manufacturing process on the hardness profile was quantified as shown in Figure 3 [data from 8]. The average hardness of the wrought sample is shown as a baseline measurement from a traditionally manufactured sample. The hardness of the AM sample exhibits small fluctuations, but is consistently around $470 \mathrm{HV}$. The AM sample hardness is lower near the region closest to the build plate and slightly increases then decreases along the build direction. The effect of the hybrid process on the hardness of the hybrid AM sample is evident in the cyclic nature of its hardness, which ranges between 300 and 500 HV. The overall hardness trend in the hybrid AM sample is lower near the build plate region and increases along the build direction. Furthermore, the hardness peaks are sharper and lower in amplitude near the build plate region and flatten but increase in amplitude with the build direction. It is also important to note that the overall trends of the AM sample and the hybrid AM sample are reversed. Thus, the hybrid process imparted cyclic properties and reversed the overall hardness trend. It is possible that the behavior observed is due to the specific hybrid process of choice and that changing parameters in the hybrid process will yield different results.
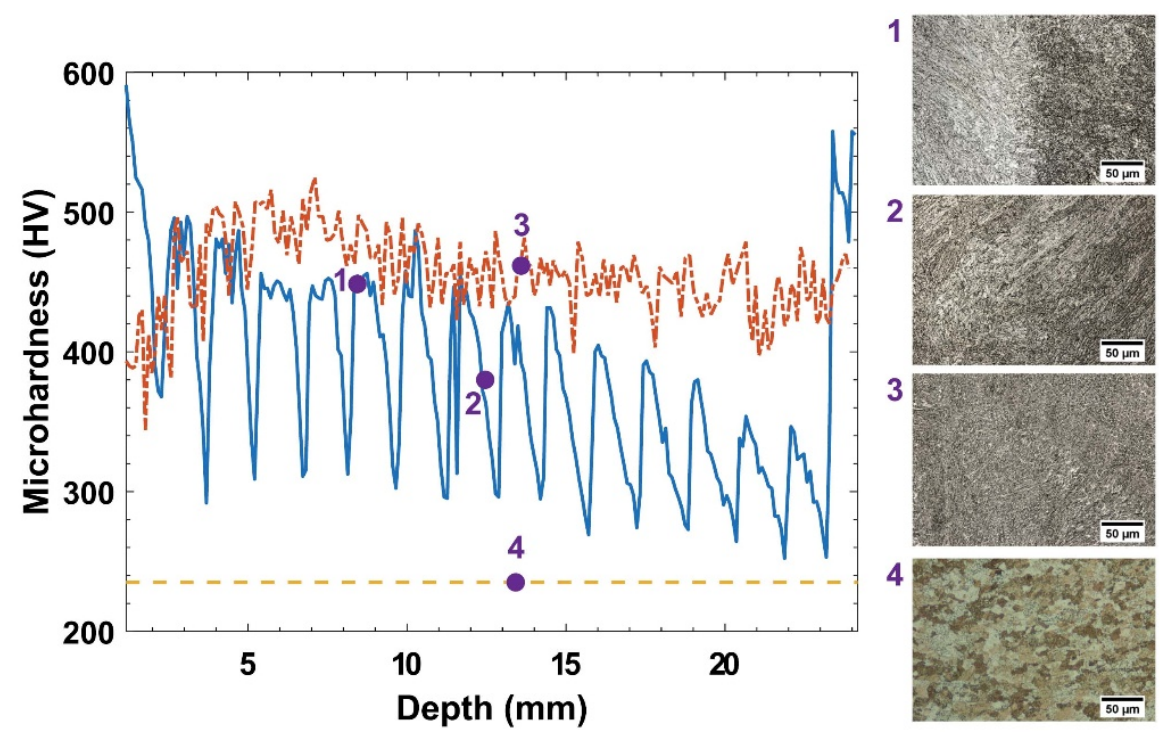

Figure 3. Vickers microhardness of hybrid AM (blue line), AM (orange dotted line), and wrought samples (gold dotted line) and examples of the corresponding microstructure at various sample locations: 1 , hybrid layer interface; 2, between hybrid layers; 3, AM; and 4, wrought. Modified from [8]. 


\subsection{Ultrasonic nondestructive characterization}

Data from ultrasound measurements were collected in a pulse-echo mode using a spherically focused broadband immersion transducer (Olympus, Waltham, MA). A DPR 300 pulser/receiver (JSR Ultrasonics, Pittsford, NY) and a 64-bit, $2 \mathrm{GHz}$ analog to digital A/D AL8xGT card (Acquisition Logic, Chantilly, VA) were used to pulse, receive, and digitize the signals. A personal computer operating UTWin software (Mistras, Princeton Junction, NJ) was used to control the data acquisition and the motion of the transducer. The transducer had a nominal center frequency of $15 \mathrm{MHz}$ and a focal length of $76.2 \mathrm{~mm}$ in water which corresponds with an approximate beam diameter of $600 \mu \mathrm{m}$ in the samples. The beam diameter is calculated using the model for a transducer beam pattern based on its Wigner distribution as described in [46]. The approximation corresponds with the beam diameter when the focus is halfway through the sample, defined as the $6 \mathrm{~dB}$ drop in amplitude of the transducer beam Wigner transform. The coherent reflections were collected from low gain signals and used to calculate the wave speed and attenuation at each point interrogated, while high gain signals were gathered to study the diffuse ultrasonic backscatter. Each measurement used a scan area of approximately $4 \times 20 \mathrm{~mm}^{2}$ with a step size of $0.25 \mathrm{~mm}$ for a total of $\sim 1600$ waveforms per scan. The scanning step size was smaller than the beam diameter to improve spatial imaging. While this scanning step size results in beam overlap, the length scale of the microstructural features $(<50 \mu \mathrm{m})$ is much smaller than the scanning step size $(250 \mu \mathrm{m})$ such that the beam is focused on a different set of grains at each step.

For the wave speed measurements, the focus was placed near the middle of each sample such that both the front wall and back wall were clearly visible and unsaturated. The signals were collected and analyzed following the cross correlation method [13] to calculate the corresponding wave speed at each point. For the attenuation experiments, the sample was set up such that the top and bottom surfaces were water/metal and metal/water interfaces, the transducer beam axis was normal to the sample's surfaces, and the transducer was focused on the back wall. A fused silica sample with a thickness of $9.4 \mathrm{~mm}$ was set up in a similar manner to be utilized as reference. The front wall and first two consecutive back walls were collected for each position in space. Then the experimental diffraction correction method described by Yu et al. [47] and Lerch and Neal [48] was used to calculate the attenuation coefficient of the sample (see Appendix A). Diffuse backscatter measurements were collected at material paths of 5 and $7 \mathrm{~mm}$ in the samples to ensure that the front wall would not mask the equivalent of a pulse width centered at the focal plane. To analyze the diffuse backscatter signals, a time window was defined with a width of the pulse and a location centered at the transducer focus as shown in Figure 4(a). Because of the spatial variation in the wave speed, the focal depth was calculated for each spatial location using the measured wave speed. Then, the integral of the rectified waveforms normalized by the $\mathrm{V}_{\max }$ [22] in this time window, 


$$
\bar{\phi}=\int_{1}^{2}|\phi(t)| d t
$$

was calculated for each scan location, as shown in Figure 4(b). The quantity $\bar{\phi}$ is proportional to the energy scattered backward into the transducer and was mapped with respect to the sample geometry as shown in Figure 4(c).

(a)

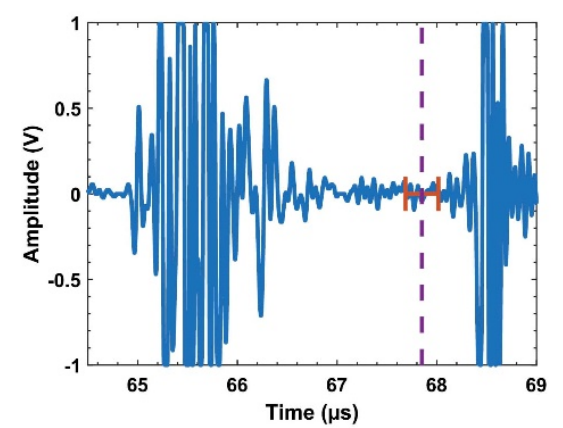

(b)

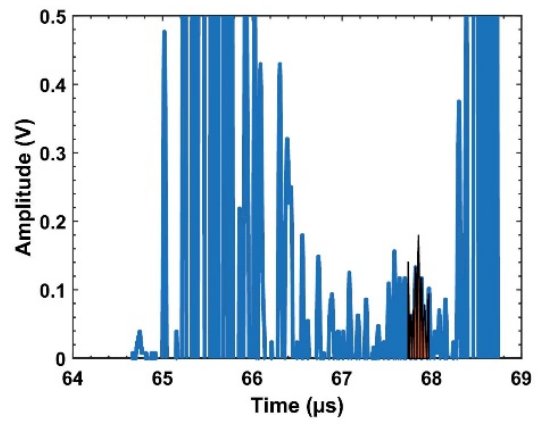

(c)

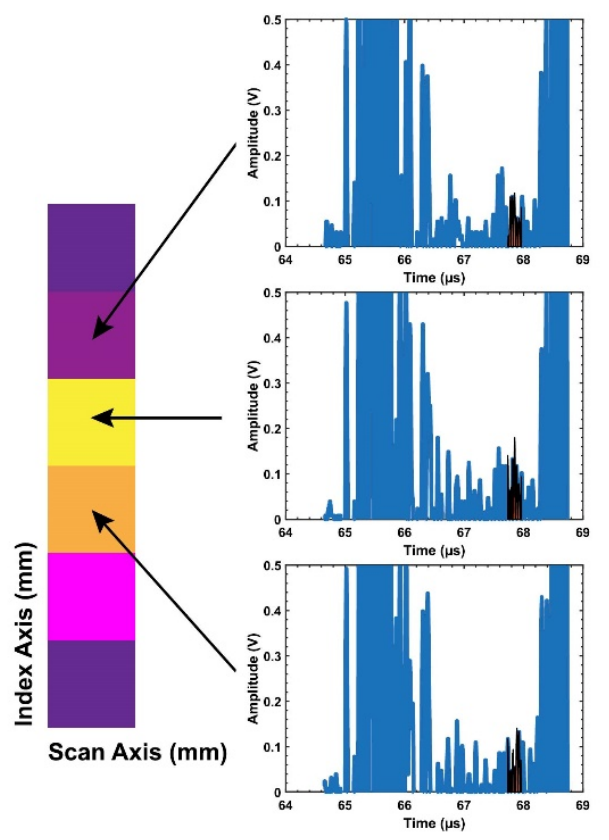

Figure 4. Processing of backscattered diffuse field signals. (a) Wave speed dependent focus location and gate, (b) integral of the rectified waveform $\bar{\phi}$, (c) schematic depicting how $\bar{\phi}$ is mapped with respect to the scanned area, where each square is a pixel. 


\section{Results and discussion}

\subsection{Property maps}

The ability of ultrasound to interrogate a wide area is illustrated in Figures 5-7, which show wave speed, attenuation, and diffuse backscatter maps respectively for all the samples. Information regarding the spatial variation of properties across each sample is easily accessible by observing these maps, including the degree of sample homogeneity, the overall trends in each sample, and indications of cyclic behavior imparted by the hybrid processing. The sensitivity to this cyclic behavior is quantified in Section 3.2. Wave speed maps of all the samples are provided in Figure 5. The wave speed in a homogeneous material is proportional to its elastic properties, which can also be related to the hardness of the material $[49,50]$. Furthermore, the wave speed is also known to be affected by the stress state of the material, and the presence of residual stresses [51]. The map in Figure 5(a), for the wrought sample, shows that there are slight spatial variations in the wave speed, but the sample appears uniform in comparison with the AM and hybrid AM samples. The average wave speed values are shown in Table 1. In addition, a decreasing gradient in the wave speed of the AM sample (Fig. 5(b)) can be observed along the build direction. Such a trend is indicative of a decrease in the elastic properties of the sample and is consistent with the measured microhardness shown in Figure 3. The hybrid sample wave speed (Fig. 5(c)) shows an increasing gradient in the build direction which denotes an increase in the sample elastic properties. This trend is consistent with the results shown in Figure 3, and the reverse trend observed between the AM and the hybrid AM microhardness data is also captured in their wave speed maps. The wave speed results also indicate that the drop in hardness observed in the AM sample near the build plate and the opposing AM and hybrid AM hardness trends are likely due to differences in the residual stress state of the samples. While the AM sample is expected to be mostly in tension, the hybrid AM process imparted compressive residual stresses in a cyclical manner resulting in the overall reversal of the residual stress trend despite the thermal cycles. These results follow the trends predicted by Maddireddy et al. [6] and observed by Sealy et al. [8] and Kalentics et al. [7]. Multiple factors affect the wave speed measurements in competing ways. The accumulation of dislocations and formation of fresh and tempered martensite are expected to lower the wave speed $[50,52,53]$. The presence of multiple phases, grain refinement, and compressive residual stresses result in faster wave travel times [50-56]. The results obtained in this study indicate a strong influence of the local and global residual stress state on the wave speed measurements. 
(a)

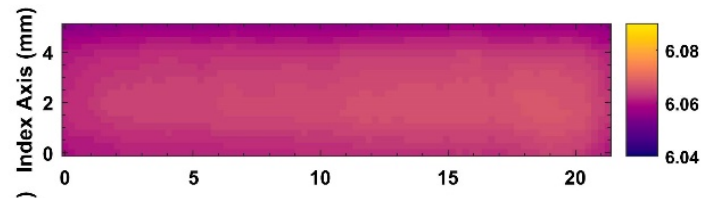

(b)

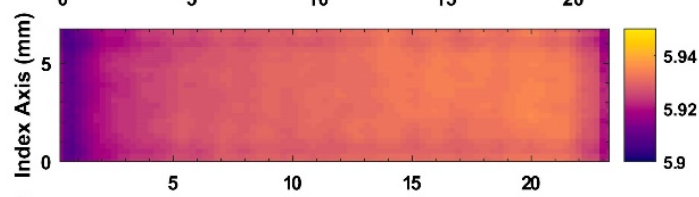

(c)

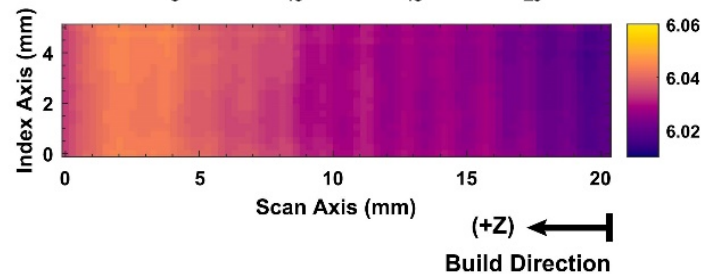

Figure 5. Ultrasonic wave speed, c (mm/ $\mu \mathrm{s})$, maps for the (a) wrought, (b) AM, and (c) hybrid AM samples. Note the differences in scale.

Table 1. Summary of averaged measured properties, namely wave speed, c, attenuation, $\alpha$, and normalized backscatter ( $\bar{\phi}$ from Equation (1)) for two different material paths (MP)

\begin{tabular}{lcccc}
\hline & $\mathrm{c}(\mathrm{mm} / \mu \mathrm{s})$ & $\alpha(\mathrm{Np} / \mathrm{m})$ & $\bar{\phi}(\mathrm{MP}=5 \mathrm{~mm})$ & $\bar{\phi}(\mathrm{MP}=7 \mathrm{~mm})$ \\
\hline Wrought & $6.06 \pm 0.00$ & $1.87 \pm 0.05$ & $0.059 \pm 0.016$ & $0.063 \pm 0.016$ \\
AM & $5.93 \pm 0.01$ & $1.91 \pm 0.05$ & $0.113 \pm 0.030$ & $0.122 \pm 0.045$ \\
Hybrid AM & $6.03 \pm 0.01$ & $2.23 \pm 0.09$ & $0.103 \pm 0.058$ & $0.107 \pm 0.048$ \\
\hline
\end{tabular}

The attenuation maps for all the samples are shown in Figure 6. For homogeneous materials, both the attenuation and the diffuse backscatter amplitude are related to the microstructure morphology [15-22]. Also, because of the Hall-Petch relationship and the influence of compressive strength on the hardness of metals, smaller grains are expected to yield higher hardness while larger grains are expected to result in lower hardness [57]. The attenuation of the wrought sample, shown in Figure 6(a), is the most uniform throughout with an average of $1.87 \pm 0.05 \mathrm{~Np} / \mathrm{m}$. The AM sample attenuation map in Figure 6(b) shows the attenuation of this sample away from the edges (an artifact of edge effects) is also mostly uniform, with an average of $1.91 \pm 0.05 \mathrm{~Np} / \mathrm{m}$. A direct comparison to published attenuation values is difficult due to the microstructure complexity. However, Kumar et al. [52] reported an attenuation of $8.29 \mathrm{~Np} / \mathrm{m}$ at $15 \mathrm{MHz}$ in a $9 \mathrm{CrMo}$ ferritic steel with microstructural features of a similar order of magnitude $(30 \mu \mathrm{m})$ in a $9 \mathrm{CrMo}$ ferritic steel with microstructural features in a similar order of magnitude. The slight discrepancy in results is attributed to material and microstructure differences. The results in Figure 6(a) and (b) suggest that the microstructure of these samples is mostly homogeneous, despite the known heterogeneity introduced by the AM process and shown in Figure 2. The higher attenuation of the AM sample also suggests that its average grain diameter is larger than that of the wrought sample. This result may be due to the considerable elongation present 
in the AM sample [58] and the effect of the prior austenitic grain boundaries as shown in Figure 2(h) and (i).

(a)

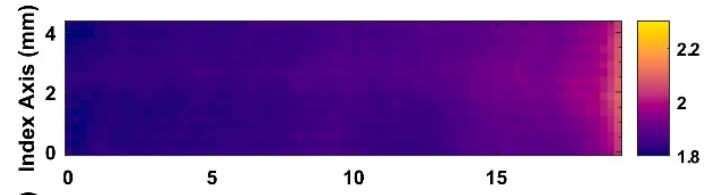

(b)

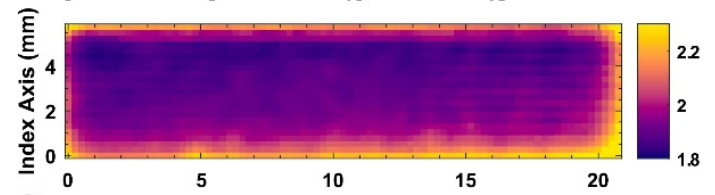

(c)

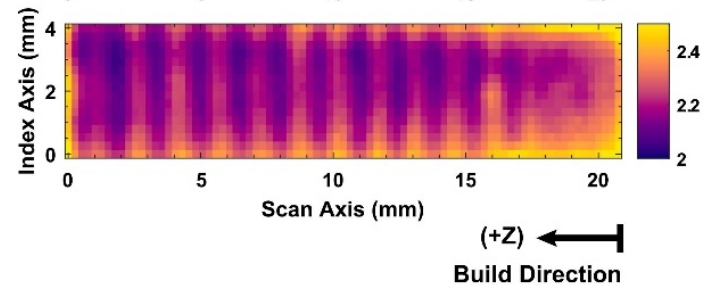

Figure 6. Attenuation, $\alpha(\mathrm{Np} / \mathrm{m})$, maps for the (a) wrought, (b) AM, and (c) hybrid AM samples. Note the differences in scale.

The attenuation map of the hybrid sample in Figure 6(c) exhibits a pronounced cyclic behavior which is primarily attributed to microstructural changes imparted by the hybrid process. The lower attenuation regions in this map are likely due to the drastic grain refinement that occurs at the hybrid layer interface as seen in Figure 2(c). The trend and cyclic behavior observed in the hybrid AM sample map are also consistent with the microhardness results shown in Figure 3. This cyclic behavior is quantified in Section 3.2.

Diffuse backscatter maps, $\bar{\phi}$ from Equation (1), for all samples are shown in Figure 7 for two different material paths, namely 5 (Fig. 7(a)-(c)) and $7 \mathrm{~mm}$ (Fig. 7(d)-(f)). The maps corresponding with the wrought sample show the least spatial variation and the lowest amplitude, both in each plane and across both material paths. The maps of the AM sample show increased spatial variation and higher backscatter amplitude in each plane, as well as higher variation across material paths. Finally, the hybrid AM sample maps show the highest spatial variation due to regions of high and low amplitude, as well as variation across material paths. At first glance, the high amplitude regions in the AM and hybrid AM maps could be attributed to the presence of voids or porosity rather than to drastic microstructural differences. However, when the AM and hybrid AM maps are thresholded as in [26] and the areas above the threshold are quantified as a percent of the total area, these regions account for $2-22 \%$ of the area. This percentage range is high in comparison with the measured averaged porosity for hybrid AM 420 stainless steel samples $(<2 \%)$. Therefore, the variations in amplitude are more likely to be indicative of the microstructural heterogeneity. Furthermore, the cyclic behavior and trends observed in the coherent measurements are not evident in these maps. Both diffuse backscatter and attenuation depend on the microstructure. However, attenuation is a metric associated with the energy 
lost from the coherent wave due to scattering in all scattering directions. Thus, it is more indicative of the average microstructure through the entire thickness of the sample. On the other hand, the normal incidence diffuse backscatter response is a metric associated with the scattering near the focal depth in the backward direction. Various local volumes of material throughout the thickness of the sample may be quantified by employing different material paths with a focused beam transducer. For these reasons, diffuse backscatter measurements offer a more localized description of the microstructure, while attenuation measurements better depict the average characteristics of the bulk.

(a)

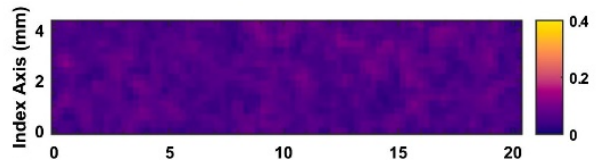

(b)

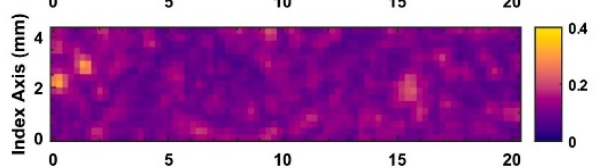

(c)

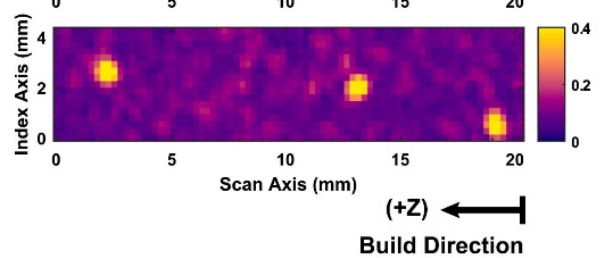

(d)

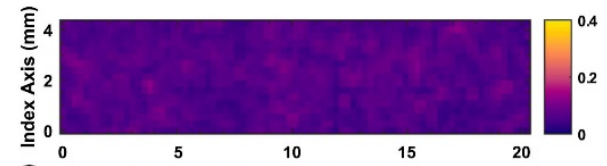

(e)

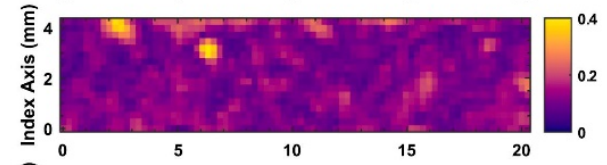

(f)

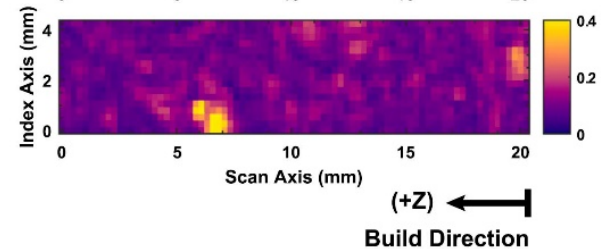

Figure 7. Normalized backscatter, $\bar{\phi}$ from Equation (1), maps for the (a) and (d) wrought, (b) and (e) AM, and (c) and(f) hybrid AM samples. (a)-(c) $5 \mathrm{~mm}$ material path, (b)-(f) 7 mm material path.

The amplitude of the diffuse backscatter can be influenced by many factors including microstructure morphology, phases, orientation, and stress state [18-26,58,59]. The complex microstructure morphology of these samples shown in Figure 2 is also highlighted. Additionally, the LP process is expected to introduce dislocations in the microstructure of the steel, promoting grain refinement [8]. Furthermore, while such characterization was beyond the scope of this work, AM materials are known to exhibit preferential grain orientations as well as residual stresses that often result in part deformation and failure [3]. The LP process also imparts compressive residual stresses on the worked surfaces, further complicating the stress state of the hybrid AM sample [8]. Given all of these effects, the variation seen in the diffuse backscatter maps is not surprising. Likewise, these maps indicate that the diffuse backscatter measurements are more sensitive than the coherent measurements to the aforementioned effects and provide additional information related to the heterogeneity of these samples.

A quantitative summary of the property maps shown in Figures 5-7 is provided in Table 1 . As expected, in all cases the wrought sample exhibits the lowest property variation, while the hybrid AM sample shows the highest variation. In terms of the wave speed, the average wave speed of the AM sample is lower than that of the wrought. The hybrid process results in an increase in average wave speed with respect to the AM process alone. 
The average attenuation of the AM sample is also higher than that of the wrought sample, while the hybrid AM sample exhibits the highest average attenuation. Both of these results are consistent with the microhardness trends in Figure 3. Finally the average backscatter amplitude, $\bar{\phi}$ from Equation (1), shows consistent results in both material paths, with the wrought sample having the lowest average magnitude, and the AM sample having the highest.

\subsection{Comparison between destructive and nondestructive measurements}

The overall agreement between destructive and nondestructive measurements is clearly displayed in Figure 8, which shows the average and standard deviation of wave speed and attenuation by column along with the microhardness data. As shown in Figure 8(a), the wave speed follows the microhardness trend and the cycles observed in the wave speed data coincide with the microhardness peaks. In Figure 8(b) the attenuation trend is shown to oppose the microhardness trend, as expected. Along the build direction, the attenuation decreases as the microhardness increases, due to microstructure refinement in the regions of lower attenuation. The peaks in the attenuation also coincide with the valleys in microhardness, which are indicative of locations with larger average grain diameter. The diffuse backscatter, $\bar{\phi}$, is not shown because it did not exhibit an explicit trend or behavior (Fig. 7).

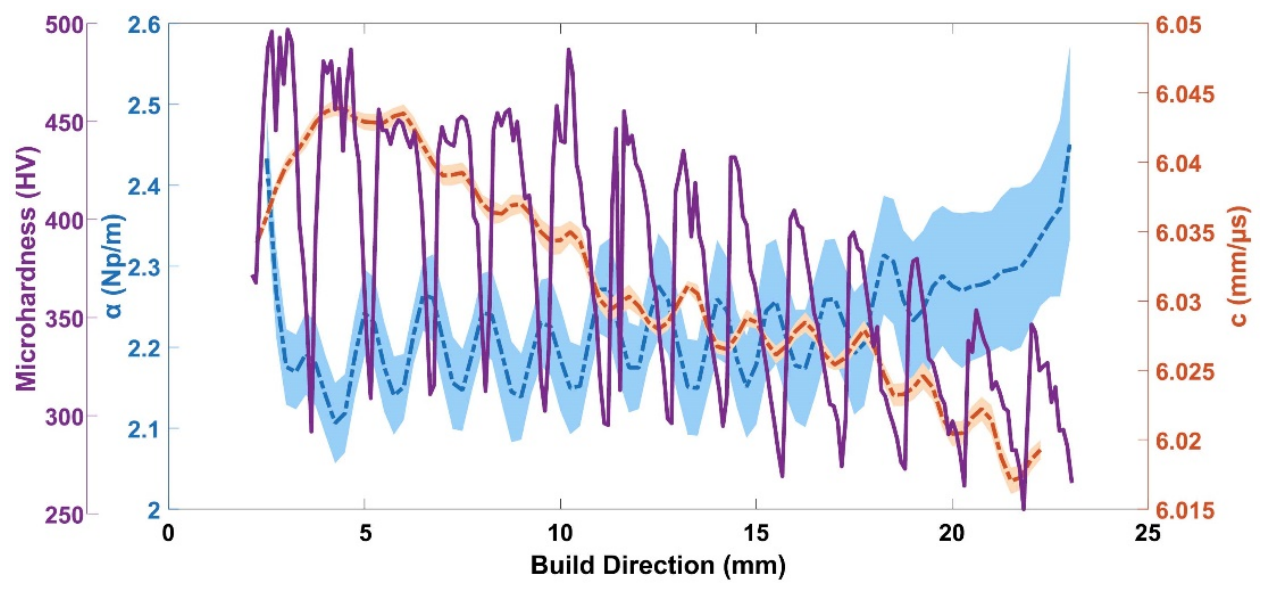

Figure 8. Ultrasonic nondestructive measurements and microhardness results along the build direction of the hybrid sample. The shaded regions indicate the standard deviation of each metric.

To quantify the resolution of ultrasound nondestructive measurements and microhardness measurements, the length of each visible cycle was determined for each measurement as the distance between the observable valleys in each measurement curve. The mean cycle length for all measurements as well as the percent error in comparison with the nominal distance between hybrid cycles $(1.5 \mathrm{~mm})$ is summarized in Table 2 . Note that due to the limitations imposed by the microhardness measurement only the resolution along the build direction is meaningful. While the microhardness had the lowest variability of all measurements, the results of wave speed and attenuation were comparable to the 
microhardness resolution, and all measurements were within a margin of about $1 \%$ error from the nominal value.

\begin{tabular}{lcc}
\hline \multicolumn{2}{l}{ Table 2. Comparison of measurement resolution } & \\
\hline Measurement & Estimated Hybrid Cycle Length $(\mathrm{mm})$ & \% Error \\
\hline Microhardness & $1.49 \pm 0.10$ & 0.7 \\
Wave Speed & $1.50 \pm 0.19$ & 0.0 \\
Attenuation & $1.48 \pm 0.14$ & 1.3 \\
\hline
\end{tabular}

Ultrasound nondestructive measurements are shown to be as effective at tracing the property changes along the build direction as well as the microhardness measurement for hybrid AM samples. Additionally, diffuse backscatter field measurements provided increased sensitivity to sample heterogeneity. Ultrasound measurements also have the advantage of being faster to collect, which allows for the rapid creation of property maps.

Nonetheless, these measurements also have limitations. Wave speed and attenuation measurements rely on controlled sample surface roughness and accurate knowledge of the geometry. It is possible that the surface roughness and/or geometry uncertainty of asprinted samples would limit the observation of the measured property changes. Different hybrid processing may impart property gradients that are more or less drastic, therefore resolvable, than those reported in this study. The resolution of the measurements is also dependent upon the ultrasonic beam parameters. If the cyclic property changes are much smaller than the beam diameter they may be undetected. In the case of the hybrid AM sample studied here, this limitation was not encountered because the hybrid process was imparted approximately every $1.5 \mathrm{~mm}$. Further limitations can be encountered due to the homogeneity assumption that often arises in ultrasound theory. The results shown here indicate that this assumption is insufficient to represent AM and Hybrid AM materials. While the limitations of the measurement are acknowledged, the ability to resolve the property gradient nondestructively is still an encouraging result with applicability for various hybrid processes in AM.

\section{Conclusion}

This study aimed to evaluate the sensitivity of ultrasound measurements to detect property changes in AM and hybrid AM samples nondestructively. For this purpose, wave speed, attenuation, and backscatter measurements of wrought, AM, and hybrid AM samples were collected perpendicular to the build direction and compared with Vickers microhardness (i.e., destructive) measurements gathered along the same direction. Relevant microscopy was also obtained for verification. The coherent ultrasound nondestructive measurements collected were shown to agree with the spatial fluctuations observed in the destructive measurements. The nondestructive and destructive methods detected the cyclic property changes in the hybrid AM sample with comparable resolution. Wave speed measurements showed a reversal in trend between the AM and the hybrid AM sample, which is attributed to the changes in residual stress state imparted by the hybrid process. 
Furthermore, diffuse ultrasound backscatter measurements displayed increased sensitivity to the heterogeneity in the samples. These results highlight the potential of localized ultrasound as a rapid and accessible nondestructive characterization method for hybrid AM samples. Additional studies may evaluate ultrasound sensitivity with respect to varying periodicity of different hybrid processes to explore the limitations of these nondestructive methods in resolving the property changes imparted. Incorporating modeling of heterogeneous domains in ultrasound theory is also an important step in understanding the information provided by diffuse backscatter measurements.

Declaration of Competing Interest - The authors declare that they have no known competing financial interests or personal relationships that could have appeared to influence the work reported in this paper.

Acknowledgments - This material is based upon work supported by the National Science Foundation Graduate Research Fellowship Program under Grant No. 1610400. Any opinions, findings, and conclusions or recommendations expressed in this material are those of the authors and do not necessarily reflect the views of the National Science Foundation. Research activities were completed in part in the Nebraska Nanoscale Facility: NSF National Nanotechnology Coordinated Infrastructure under award no. ECCS: 1542182, and the Nano-Engineering Research Core Facility at the University of Nebraska-Lincoln, supported by the Nebraska Research Initiative and by NSF CMMI: 1846478. The authors also would like to acknowledge the financial support from Jazan University for Haitham Hadidi. The research was facilitated by the Laser Assisted Nano Engineering Lab under the direction of Dr. Yongfeng Lu. Finally, the authors wish to acknowledge Nathanial J. Matz for his useful input during the data analysis.

\section{Appendix A}

Using the experimental diffraction correction method described by Yu et al. [47] and Lerch and Neal [48], the attenuation coefficient of a sample may be calculated as:

$$
\alpha_{S}=\frac{1}{2 z_{S}} \ln \left(\frac{B_{r}(\omega) R_{S}\left(1-R_{S}^{2}\right)}{B_{S}(\omega) R_{r}\left(1-R_{r}^{2}\right)}\right) \exp \left(2 \alpha_{f}\left(z_{f r}-z_{f S}\right)\right)
$$

where $\alpha_{s}$ is the attenuation in the sample, $z_{s}$ is the sample thickness, $B_{r}(\omega)$ is the amplitude of the first back wall reflection of the reference sample, $B_{s}(\omega)$ is the amplitude of the first back wall reflection of the sample, $R_{s}$ is the sample reflection coefficient, $R_{r}$ is the reference sample reflection coefficient, $\alpha_{f}$ is the attenuation in the fluid, and, $z_{f r}-z_{f s}$ is the difference between the water paths used for the sample and reference sample.

To calculate the attenuation coefficient, the authors used the measured average wave speed and density of all samples and theoretical values for water to calculate the corresponding reflection coefficients. The authors also assumed a theoretical value for the attenuation in water. 


\section{References}

[1] National Academies of Sciences, Engineering, and Medicine, Securing Advanced Manufacturing in the United States: The Role of Manufacturing USA: Proceedings of a Workshop. The National Academies Press, Washington, DC, 2017. https://doi.org/10.17226/24875.

[2] J. Bishop-Moser, L. Bond, G. Georgeson, W. Hassan, S. Telesz, P. Zombo, L. Jacobs, R. Klaassen, C. Leckey, Rapid reliability assessment of safety-critical and emerging technologies, MForesight. (2019). http://mforesight.org/projects-events/nde/.

[3] W.J. Sames, F.A. List, S. Pannala, R.R. Dehoff, S.S. Babu, The metallurgy and processing science of metal additive manufacturing, Int. Mater. Rev. 61 (5) (2016) 315-360.

[4] M.P. Sealy, G. Madireddy, R.E. Williams, P. Rao, M. Toursangsaraki, Hybrid processes in additive manufacturing, J. Manuf. Sci. Eng. 140 (6) (2018), https://doi.org/10.1115/1.4038644.

[5] M.P. Sealy, G. Madireddy, C. Li, Y.B. Guo. Finite element modeling of hybrid additive manufacturing by laser shock peening, United States, Austin, 2016, pp. 306-316.

[6] G. Madireddy, C. Li, J. Liu, M.P. Sealy, Modeling thermal and mechanical cancellation of residual stress from hybrid additive manufacturing by laser peening, Nanotechnol. Precision Eng. 2(2), 49-60. https://doi.org/10.1016/j.npe.2019.07.001.

[7] N. Kalentics, E. Boillat, P. Peyre, C. Gorny, C. Kenel, C. Leinenbach, J. Jhabvala, R. E. Logé, 3D Laser Shock Peening - A new method for the 3D control of residual stresses in Selective Laser Melting, Mater. Des. 130 (2017) 350-356.

[8] M.P. Sealy, H. Hadidi, C.J. Kanger, X.L. Yan, B. Cui, J.A. McGeough, Glocal integrity in 420 stainless steel by asynchronous laser processing, CIRP Ann. 68 (1) (2019) 189-192.

[9] Z.D. Wang, G.F. Sun, Y. Lu, M.Z. Chen, K.D. Bi, Z.H. Ni, Microstructural characterization and mechanical behavior of ultrasonic impact peened and laser shock peened AISI 316L stainless steel, Surf. Coat. Technol. 385 (2020) 125403, https://doi.org/10.1016/j.surfcoat.2020.125403.

[10] D.A. Lesyk, H. Soyama, B.N. Mordyuk, V.V. Dzhemelinskyi, S. Martinez, N. I. Khripta, A. Lamikiz, Mechanical surface treatments of AISI 304 stainless steel: effects on surface microrelief, residual stress, and microstructure, J. Mater. Eng. Perform. 28 (9) (2019) 5307-5322.

[11] X. Chen, Y. Fang, S. Zhang, J.F. Kelleher, J. Zhou, Effects of LSP on micro-structures and residual stresses in a 4 mm CLAM steel weld joints, Fusion Eng. Des. 94 (2015) 54-60.

[12] H.M. Ledbetter, N.V. Frederick, M.W. Austin, Elastic-constant variability in stainless-steel 304, J. Appl. Phys. 51 (1) (1980) 305-309.

[13] D.R.K. Hull, Ultrasonic velocity measurement using phase-slope cross-correlation methods. 1984 Spring Conf. of the Am. Soc. for Nondestructive Testing, Denver, CO, United States, 1984, January 1. https://ntrs.nasa.gov/search.jsp?R=19 840026698.

[14] R.J. Smith, W. Li, J. Coulson, M. Clark, M.G. Somekh, S.D. Sharples, Spatially resolved acoustic spectroscopy for rapid imaging of material microstructure and grain orientation, Meas. Sci. Technol. 25 (5) (2014) 055902, https://doi.org/10.1088/0957-0233/25/5/055902.

[15] W.P. Mason, H.J. McSkimin, Attenuation and scattering of high frequency sound waves in metals and glasses, J. Acoust. Soc. Am. 19 (3) (1947) 464-473.

[16] Fred E. Stanke, G.S. Kino, A unified theory for elastic wave propagation in polycrystalline materials, J. Acoust. Soc. Am. 75 (3) (1984) 665-681.

[17] R.L. Weaver, Diffusivity of ultrasound in polycrystals, J. Mech. Phys. Solids 38 (1) (1990) 55-86.

[18] S. Ahmed, R.B. Thompson, Propagation of elastic waves in equiaxed stainless-steel polycrystals with aligned [001] axes, J. Acoust. Soc. Am. 99 (4) (1996) 2086-2096. 
[19] J.H. Rose, Ultrasonic Backscattering from Polycrystalline Aggregates using Time-Domain Linear Response Theory, in: D.O. Thompson, D.E. Chimenti (Eds.), Review of Progress in Quantitative Nondestructive Evaluation, Volume 10B, Springer, US, 1991, pp. 1715-1720, https://doi.org/ 10.1007/978-1-4615-3742-7_75.

[20] F.J. Margetan, T.A. Gray, R.B. Thompson, A Technique for quantitatively measuring microstructurally induced ultrasonic noise, in: D.O. Thompson, D. E. Chimenti (Eds.), Review of Progress in Quantitative Nondestructive Evaluation, Springer, US, 1991, pp. 1721-1728, https://doi.org/ 10.1007/978-1-4615-3742-7_76.

[21] R. Bruce Thompson, F.J. Margetan, P. Haldipur, L. Yu, A. Li, P. Panetta, H. Wasan, Scattering of elastic waves in simple and complex polycrystals, Wave Motion 45 (5) (2008) 655-674.

[22] G. Ghoshal, J.A. Turner, Diffuse ultrasonic backscatter at normal incidence through a curved interface, J. Acoust. Soc. Am. 128 (6) (2010) 3449-3458.

[23] P. Hu, C.M. Kube, L.W. Koester, J.A. Turner, Mode-converted diffuse ultrasonic backscatter, J. Acoust. Soc. Am. 134 (2) (2013) 982-990.

[24] P. Hu, J.A. Turner, Transverse-to-transverse diffuse ultrasonic scattering, J. Acoust. Soc. Am. 142 (2) (2017) 1112-1120.

[25] A.P. Arguelles, C.M. Kube, P. Hu, J.A. Turner, Mode-converted ultrasonic scattering in polycrystals with elongated grains, J. Acoust. Soc. Am. 140 (3) (2016) 1570-1580.

[26] Y. Song, C.M. Kube, J.A. Turner, X. Li, Statistics associated with the scattering of ultrasound from microstructure, Ultrasonics 80 (2017) 58-61.

[27] L.W. Koester, L.J. Bond, H. Taheri, P.C. Collins, Nondestructive evaluation of additively manufactured metallic parts: In situ and post deposition, in: F. Froes, R. Boyer (Eds.), Additive Manufacturing for the Aerospace Industry, Elsevier, 2019, pp. 401-417. 10.1016/B978-0-12814062-8.00020-0.

[28] B. Chassignole, V. Duwig, M.-A. Ploix, P. Guy, R. El Guerjouma, Modelling the attenuation in the ATHENA finite elements code for the ultrasonic testing of austenitic stainless steel welds, Ultrasonics 49 (8) (2009) 653-658.

[29] B. Chassignole, R. El Guerjouma, M.-A. Ploix, T. Fouquet, Ultrasonic and structural characterization of anisotropic austenitic stainless steel welds: Towards a higher reliability in ultrasonic non-destructive testing, NDT and E Int. 43 (4) (2010) 273-282.

[30] M.-A. Ploix, P. Guy, B. Chassignole, J. Moysan, G. Corneloup, R.E. Guerjouma, Measurement of ultrasonic scattering attenuation in austenitic stainless steel welds: Realistic input data for NDT numerical modeling, Ultrasonics 54 (7) (2014) 1729-1736.

[31] J.A. Slotwinski, E.J. Garboczi, K.M. Hebenstreit, Porosity measurements and analysis for metal additive manufacturing process control, J. Res. Natl. Instit. Standards Technol. 119 (2014) 494528, https://doi.org/10.6028/jres.119.019.

[32] N.V. Karthik, H. Gu, D. Pal, T. Starr, B. Stucker, High frequency ultrasonic nondestructive evaluation of additively manufactured components, in: 24th International Solid Freeform Fabrication Symposium, 2013, August, pp. 311-325.

[33] R.J. Smith, M. Hirsch, R. Patel, W. Li, A.T. Clare, S.D. Sharples, Spatially resolved acoustic spectroscopy for selective laser melting, J. Mater. Process. Technol. 236 (2016) 93-102.

[34] Y. Song, X. Zi, Y. Fu, X. Li, C. Chen, K. Zhou, Nondestructive testing of additively manufactured material based on ultrasonic scattering measurement, Measurement 118 (2018) 105-112.

[35] A. Bellotti, J.-Y. Kim, J.E. Bishop, B.H. Jared, D. Susan, L.J. Jacobs, Nonlinear ultrasonic technique for the quantification of dislocation density in additive materials. AIP Conference Proceedings, 2102(1), 020040, 2019. https://doi.org/10.1063/1.5099744. 
[36] D. Cerniglia, M. Scafidi, A. Pantano, J. Rudlin, Inspection of additive-manufactured layered components, Ultrasonics 62 (2015) 292-298.

[37] H. Rieder, M. Spies, J. Bamberg, B. Henkel, On- and offline ultrasonic characterization of components built by SLM additive manufacturing, AIP Conf. Proc. 1706 (1) (2016), 130002, https://doi.org/10.1063/1.4940605.

[38] C.M. Kube, Y. Shu, A.J. Lew, D. Galles, Real-Time Characterization of Laser-Generated Melt Pools using Ultrasound, Mater. Eval. 11 (2018).

[39] D. Pieris, R. Patel, P. Dryburgh, M. Hirsch, W. Li, S.D. Sharples, R.J. Smith, A. T. Clare, M. Clark, Spatially Resolved Acoustic Spectroscopy Towards Online Inspection of Additive Manufacturing, insight 61 (3) (2019) 132-137.

[40] Subrata Deb Nath, Harish Irrinki, Gautam Gupta, Martin Kearns, Ozkan Gulsoy, Sundar Atre, Microstructure-property relationships of 420 stainless steel fabricated by laser-powder bed fusion, Powder Technol. 343 (2019) 738-746.

[41] ASTM International. E3-11(2017) Standard Guide for Preparation of Metallographic Specimens. West Conshohocken, PA; ASTM International. https://doi-org.libproxy.unl.edu/10.1520/ E0003-11R17.

[42] ASTM International, e1 Standard Practice for Microetching Metals and Alloys, West Conshohocken, PA; ASTM E407-07 (2015) (International.https://doi-org.libproxy. unl.edu/10.1520/ E0407-07R15E01.).

[43] S.H. Baghjari, S.A.A. Akbari Mousavi, Effects of pulsed Nd:YAG laser welding parameters and subsequent post-weld heat treatment on microstructure and hardness of AISI 420 stainless steel, Mater. Des. 43 (2013) 1-9.

[44] P. Krakhmalev, I. Yadroitsava, G. Fredriksson, I. Yadroitsev, In situ heat treatment in selective laser melted martensitic AISI 420 stainless steels, Mater. Des. 87 (2015) 380-385.

[45] K. Saeidi, D.L. Zapata, F. Lofaj, L. Kvetkova, J. Olsen, Z. Shen, F. Akhtar, Ultra-high strength martensitic 420 stainless steel with high ductility, Addit. Manuf. 29 (2019) 100803, https://doi.org/ 10.1016/j.addma.2019.100803.

[46] G. Ghoshal, J.A. Turner, R.L. Weaver, Wigner distribution of a transducer beam pattern within a multiple scattering formalism for heterogeneous solids, J. Acoust. Soc. Am. 122 (4) (2007) 2009-2021.

[47] L. Yu, Y. Guo, F.J. Margetan, R.B. Thompson, Effect of microstructure on backwall signal attenuation measurements using focused transducers, AIP Conf. Proc. 557 (1) (2001) 1330-1337, https://doi.org/10.1063/1.1373908.

[48] T.P. Lerch, S.P. Neal, Attenuation coefficient estimation using equivalent diffraction points with multiple interface reflections, AIP Conf. Proc. 657 (1) (2003) 1759-1768, https://doi.org/ 10.1063/1.1570342.

[49] Y.-T. Cheng, C.-M. Cheng, Relationships between hardness, elastic modulus, and the work of indentation, Appl. Phys. Lett. 73 (5) (1998) 614-616.

[50] C.-H. Hsu, H.-Y. Teng, Y.-J. Chen, Relationship between ultrasonic characteristics and mechanical properties of tempered martensitic stainless steel, J. Mater. Eng. Perform. 13 (5) (2004) 593-599.

[51] Y. Javadi, K. Azari, S.M. Ghalehbandi, M.J. Roy, Comparison between using longitudinal and shear waves in ultrasonic stress measurement to investigate the effect of post-weld heat-treatment on welding residual stresses, Res. Nondestr. Eval. 28 (2) (2017) 101-122.

[52] A. Kumar, K. Laha, T. Jayakumar, K.B.S. Rao, B. Raj, Comprehensive microstructural characterization in modified $9 \mathrm{Cr}-1 \mathrm{Mo}$ ferritic steel by ultrasonic measurements, Metall. Mat. Trans. A 33 (6) (2002) 1617-1626. 
[53] C.H. Gür, B.O. Tuncer, Characterization of microstructural phases of steels by sound velocity measurement, Mater. Charact. 55 (2) (2005) 160-166.

[54] H.H. Boukani, S.M. Chentouf, M. Viens, A. Tahan, M. Gagnon, The effect of martensitic stainless steel microstructure on the ultrasonic inspection of turbine runner joints, AIP Conf. Proc. 1650 (1) (2015) 909-916, https://doi.org/10.1063/1.4914696.

[55] A.I. Lavrentyev, W.A. Veronesi, Ultrasonic measurement of residual stress in shot peened aluminum alloy, AIP Conf. Proc. 557 (1) (2001) 1472-1479, https://doi.org/10.1063/1.1373927.

[56] P. Palanichamy, M. Vasudevan, T. Jayakumar, Measurement of residual stresses in austenitic stainless steel weld joints using ultrasonic technique, Sci. Technol. Weld. Joining 14 (2) (2009) $166-171$.

[57] M. Aghaie-Khafri, F. Honarvar, S. Zanganeh, Characterization of grain size and yield strength in AISI 301 stainless steel using ultrasonic attenuation measurements, J. Nondestruct. Eval. 31 (3) (2012) 191-196.

[58] S. Ahmed, R. Thompson, Effect of preferred grain orientation and grain elongation on ultrasonic wave propagation in stainless steel. 11 (1992).

[59] C.M. Kube, H. Du, G. Ghoshal, J.A. Turner, Stress-dependent changes in the diffuse ultrasonic backscatter coefficient in steel: Experimental results, J. Acoust. Soc. Am. 132 (1) (2012) EL43EL48. 